\title{
Congenital Ulnar Carpal Bone Luxation in a Miniature Donkey Treated by Pancarpal Arthrodesis
}

\author{
Mickaël Patrice Robert ${ }^{1}$ Yolandi Smit ${ }^{1}$ \\ ${ }^{1}$ Department of Companion Animal Clinical Studies, Faculty of Veterinary \\ Science, University of Pretoria, Onderstepoort, South Africa \\ Address for correspondence Mickaël Patrice Robert, DVM, MSc, \\ Department of Companion Animal Clinical Studies, Faculty of \\ Veterinary Science, University of Pretoria, Private Bag X04, 0110 \\ VCOT Open 2020;3:e33-e39. \\ Onderstepoort, South Africa (e-mail: dr.mickael.robert@gmail.com).
}

\author{
Abstract \\ Keywords \\ - donkey \\ - pancarpal arthrodesis \\ - carpal bone luxation \\ - congenital \\ abnormality \\ - locking compression \\ plates
}

An 18-month-old miniature donkey was presented for evaluation and treatment of a left carpal valgus present since birth. Clinical examination confirmed the severe and unstable carpal valgus. Radiographs and computed tomography revealed a caudally luxated ulnar carpal bone, malformation of the distal radial epiphysis, as well as a complete collapse of the lateral part of the radiocarpal joint. Outward rotation of the limb distal to the joint collapse was also visible. Surgical treatment was elected and a pancarpal arthrodesis performed using two short $3.5 \mathrm{~mm}$ locking compression plates. Ten months later, the donkey was pasture sound and radiographs showed complete fusion of the carpal joints.

\section{Introduction}

Miniature horses and donkeys are commonly affected by congenital diseases, especially affecting the musculoskeletal system. Stifle conditions, shoulder dysplasia, flexural and angular limb deformities appear more common than in large breeds. ${ }^{1,2}$ Because of the small size of these animals and limited growth potential, aggressive surgical techniques such as osteotomies and/or arthrodesis are sometimes required to correct severe or lately diagnosed limb deformities. ${ }^{2-5}$ These procedures generally carry a reasonable prognosis thanks to the low weight and limited athletic expectations on these small animals.

This article presents a case of severe and unstable carpal valgus due to a congenital ulnar carpal bone luxation in a young donkey, treated with pancarpal arthrodesis.

\section{Case History}

A one- and a half-year old miniature donkey gelding, weighing $44 \mathrm{~kg}$, was presented to the Onderstepoort Equine Clinic for investigation and potential treatment of a severe left carpal valgus present since birth. This condition had apparently never been addressed. The current owner acquired him when he was 8 months old from a breeder that was unable to sell him due to his carpal joint abnormalities. Over the last 3 weeks prior to presentation, the valgus deformity of the left carpus seemed to have increased in severity and the donkey appeared more painful on the affected limb.

\section{Clinical Findings}

On presentation, the donkey was bright and alert and was able to walk using all four limbs. A severe left carpal valgus was clearly visible as well as a marked outward rotation of the left front foot and metacarpus. Obvious laxity was noted when walking. Axial positioning of the right forelimb at rest was also visible ( - Fig. 1). Mobilization of the left carpus was apparently pain free, showed a normal range of sagittal motion when flexed, but marked abnormal mediolateral movements were observed.

Clinical examination was unremarkable otherwise.

\section{Diagnosis}

Radiographic examination of both carpi was undertaken. Dorsopalmar, lateromedial, dorsolateral-palmaromedial oblique and dorsomedial-palmarolateral oblique views were obtained.

The left forelimb displayed a severe carpal valgus of 16 degrees. On the left carpus, caudal positioning and/or luxation of the ulnar carpal bone were observed, resulting in a collapse of the lateral part of the radiocarpal joint. The received

December 11, 2019

accepted

April 8, 2020
DOI https://doi.org/

10.1055/s-0040-1710503. ISSN 2625-2325.
๑) 2020 Georg Thieme Verlag KG
Stuttgart · New York

License terms

(1)(1) 


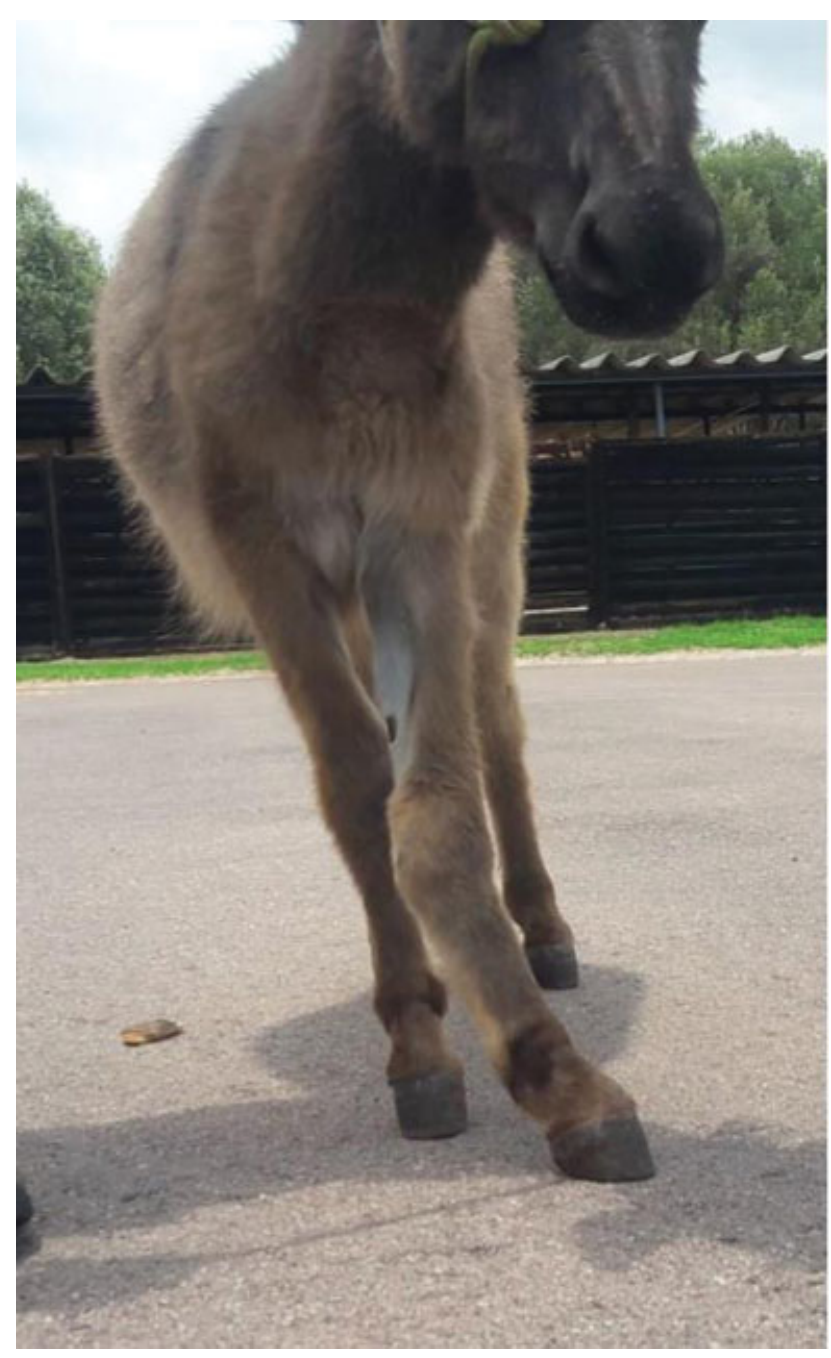

Fig. 1 Donkey upon presentation. Note the severe left carpal valgus, marked outward rotation of the left front foot and metacarpus and the axial positioning of the right forelimb at rest. distal epiphysis of the radius appeared misshaped with a prominent lateral portion (-Fig. 2 ).

The right carpus had a lesser valgus of 8 degrees. However, the ulnar carpal bone also seemed more caudally positioned than normal.

Pre-anaesthetic haematology, fibrinogen and creatinine levels were all within normal limits. The day after presentation, the donkey underwent computed tomography (Siemens Somaton Emotion Duo, Siemens, Germany) of his carpi under general anaesthesia to get a better understanding of the carpal changes.

After he had been sedated with detomidine (Equidine, Virbac South Africa, Centurion, South Africa) $10 \mu \mathrm{g} / \mathrm{kg}$ bodyweight (bwt) intravenous (IV) and morphine (morphine $10 \mathrm{mg}$ injection, Aspen Pharmacare, Durban, South Africa) $0.1 \mathrm{mg} / \mathrm{kg}$ bwt IV, general anaesthesia was induced with diazepam (Pax Injection, Aspen Pharmacare, Durban, South Africa) $0.1 \mathrm{mg} / \mathrm{kg}$ bwt IV and ketamine (Ketamine Fresenius, Fresenius Kabi, Midrand, South Africa) $2 \mathrm{mg} / \mathrm{kg}$ bwt IV and the donkey was positioned in right lateral recumbency under isoflurane (Isofor, Safeline Pharmaceuticals, Johannesburg, South Africa) in oxygen with a circle system with positive pressure ventilation.

Computed tomography of the left carpus confirmed the abnormally caudal position of the ulnar carpal bone as well as cranial displacement of the distal lateral radius and a general malformation of the distal radial epiphysis. Complete collapse of the lateral part of the radiocarpal joint was again obvious (-Fig. 3 ). Outward rotation of the limb distal to the joint collapse was also visible.

On the right carpus, milder changes were visible even though the ulnar carpal bone was more caudally positioned and the distolateral radius more pointy than usual.

Because of the suspected congenital luxation of the ulnar carpal bone and associated instability of the left carpus and poor quality of life foreseen for this donkey if left untreated, consent was obtained to perform a pancarpal arthrodesis.

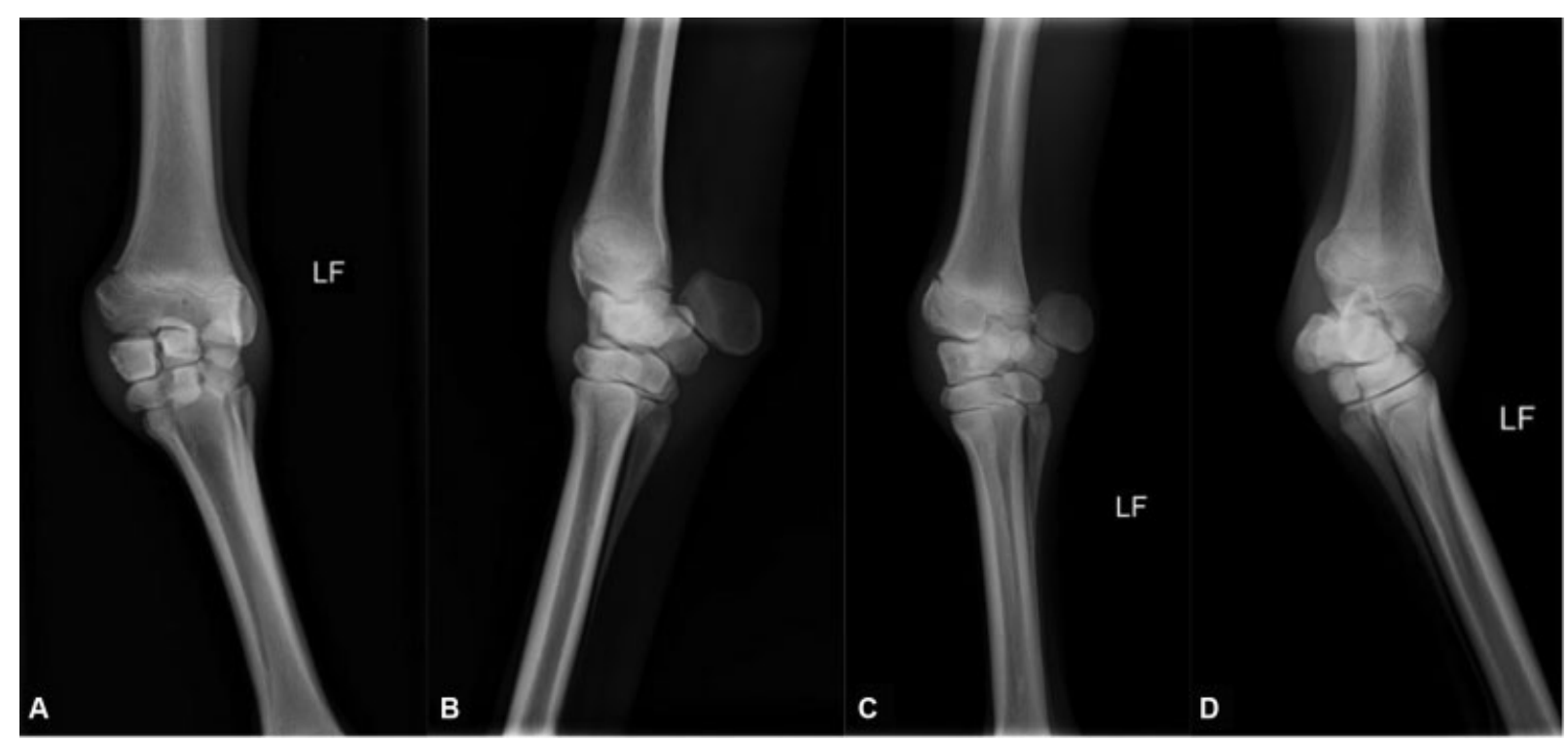

Fig. 2 Dorsopalmar (A), lateromedial (B), dorsolateral-palmaromedial oblique (C) and dorsomedial-palmarolateral (D) oblique views of the left carpus. Note the severe carpal valgus as well as luxation of the ulnar carpal bone resulting in a collapse of the lateral part of the radiocarpal joint. The distal epiphysis of the radius also appeared misshaped. 


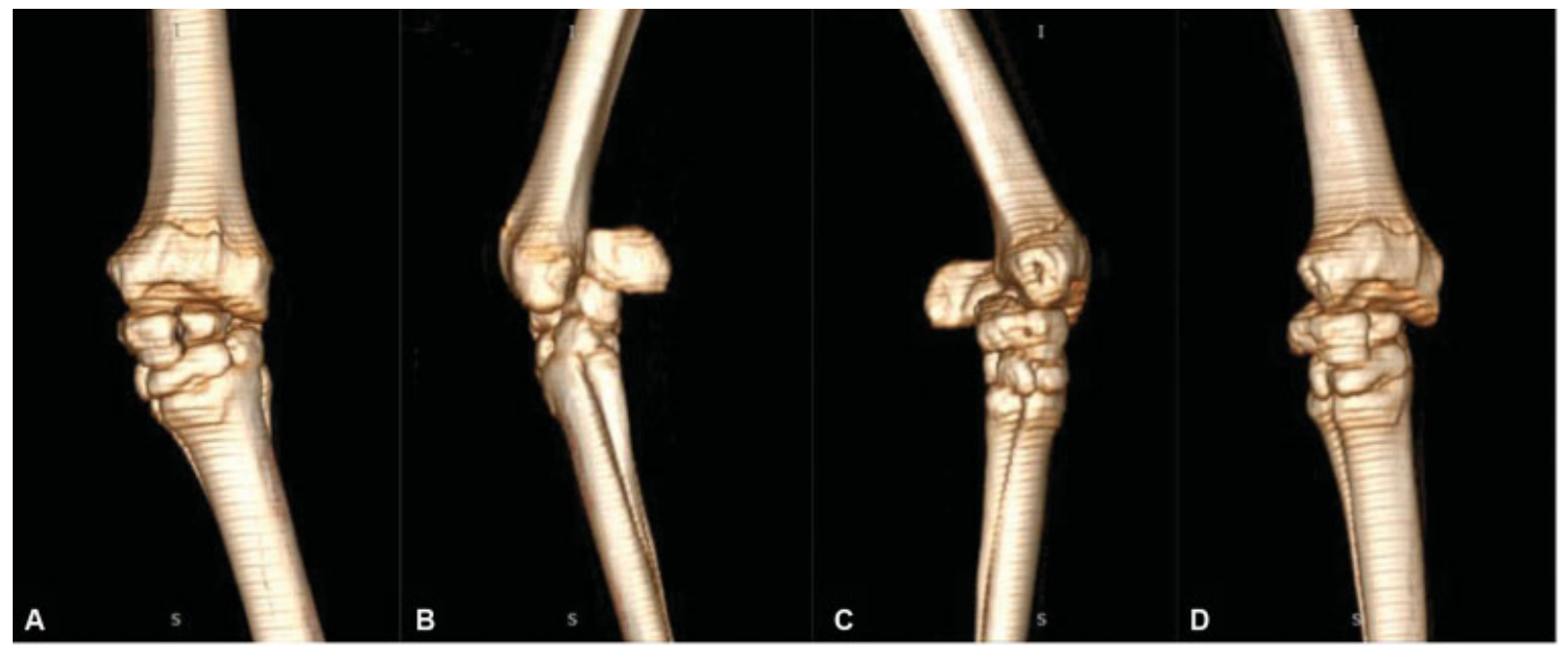

Fig. 3 Three-dimensional reconstruction of the left carpus: (A) dorsal view, (B) lateral view, (C) medial view, (D) dorsomedial view. Note the caudally luxated ulnar carpal bone, the complete collapse of the lateral part of the radiocarpal joint and the outward rotation of the distal limb.

\section{Treatment}

The donkey was transferred to the operating room and moved into dorsal recumbency with his left forelimb attached to an overhead hoist. Flunixin meglumine (Finadyne, MSD, Kempton Park, South Africa) $1.1 \mathrm{mg} / \mathrm{kg}$ bwt IV, procaine penicillin (Depocillin, MSD, Kempton Park, South Africa) $22000 \mathrm{IU} / \mathrm{kg}$ bwt intramuscular and gentamicin (Genta 40, MSD, Kempton Park, South Africa) $6.6 \mathrm{mg} / \mathrm{kg}$ bwt IV were administered. The limb was clipped from the coronary band to the elbow, surgically prepared and aseptically draped. A $15 \mathrm{~cm}$ long linear incision was performed, centred on the dorsolateral aspect of the carpus, adjacent to the tendon of the extensor carpi radialis muscle. The skin, subcutaneous tissue, joint capsule and periosteum covering the distal radius and proximal metacarpus were incised. The abnormally shaped distal radius as well as lateral collapse of the radiocarpal joint was visible (-Fig. 4). After flexion of the carpus had been obtained lowering the hoist, the articular cartilage was removed in all three carpal joints, sparing the collateral ligaments, using curettes and a motorized burr (Dremel, Racine, Wisconsin, United States) with continuous irrigation using sterile saline. Osteostixis was performed using a $2.5 \mathrm{~mm}$ drill bit on the exposed articular surfaces. Traction was then applied using the hoist to extend and align the limb as much as possible. A 7-hole narrow $3.5 \mathrm{~mm}$ locking compression plate (LCP, DePuy Synthes, Midrand, South Africa) was contoured and applied to the dorsomedial aspect of the carpus, creating compression across the carpal joints. Similarly a 6-hole $3.5 \mathrm{~mm}$ LCP was applied on the dorsolateral aspect of the joint. Three locking head screws (LHS) and three cortical screws were used in the longer plate, whereas two LHS and three cortical screws were used in the shorter plate (-Fig. 5). Particular attention was given to place a cortical screw in the luxated carpal bone to incorporate it into the construct and possibly reduce its displacement. This hybrid construct allowed a good bone-plate contact, creation of compression across the joints, purchase of the screws into several carpal bones with minimal screw

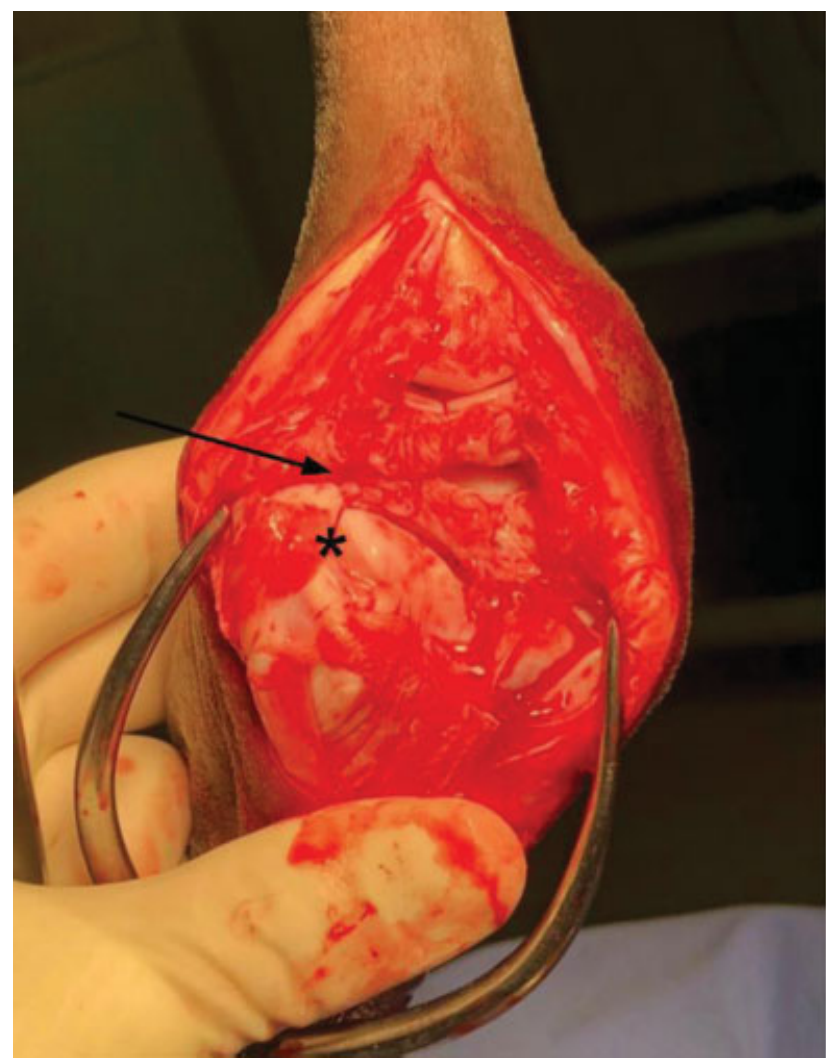

Fig. 4 Intraoperative photograph illustrating the abnormally shaped distal radius (asterisk) as well as lateral collapse of the radiocarpal joint (arrow) after incising the skin, subcutaneous tissue, joint capsule and periosteum covering the distal radius and proximal metacarpus. Top of the picture is distal, left if lateral.

interference, with the advantages of the fixed angle construct of the LCP and LHS. ${ }^{6}$ The surgical site was rinsed with sterile saline and the wound sutured in two layers. The limb was then placed in a Robert-Jones bandage with a caudal splint from the elbow joint to the fetlock.

Recovery was manually assisted and uneventful. The donkey directly bore weight on the operated limb. 


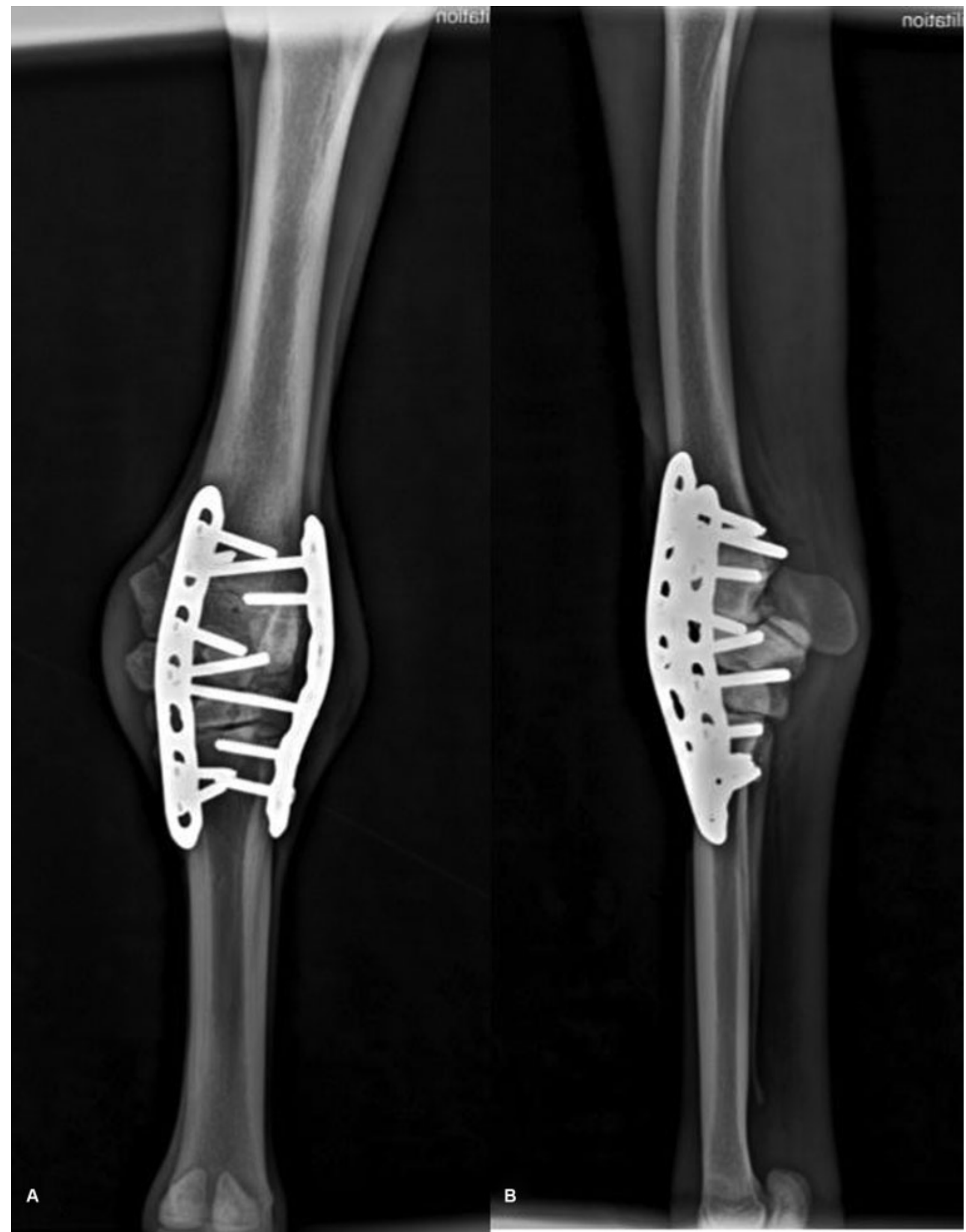

Fig. 5 Radiographs of the left carpus in the immediate postoperative period with a dorsomedial 7-hole 3.5 mm locking compression plate and a dorsolateral 6-hole $3.5 \mathrm{~mm}$ locking compression plate: (A) dorsopalmar view, (B) lateromedial view.

In the postoperative period, he was given morphine once the night following the procedure and flunixin meglumine was administered twice a day for 2 days then once a day for 3 days. Procaine penicillin and gentamicin were given for 5 days. Omeprazole (Omepracote, Ascendis Animal Health,
Cape Town, South Africa) $2 \mathrm{mg} / \mathrm{kg}$ bwt per os (PO) was also administered to prevent gastric ulceration.

The bandage was changed on the third postoperative day. The surgical site was clean and dry. A similar bandage was applied with the caudal splint on. The donkey was discharged 
4 days after the arthrodesis with recommendations given to keep him in a small stable and to administer trimethoprimsulfamethoxazole (Purbac, Pharmacare Limited, Port Elizabeth, South Africa) $25 \mathrm{mg} / \mathrm{kg}$ bwt PO twice a day for 5 days, meloxicam (Coxflam, Cipla South Africa, Cape Town, South Africa) $0.6 \mathrm{mg} / \mathrm{kg}$ bwt PO once a day for 10 days and omeprazole $2 \mathrm{mg} / \mathrm{kg}$ bwt PO once a day for 10 days.

\section{Outcome}

The donkey was presented 2 weeks after the procedure. He was putting weight on the operated limb despite a tendency to drag it because of the bandage bulk. The bandage was removed and the limb inspected. It appeared straight in both frontal and sagittal planes with a mild outward rotation of the distal limb. The surgical site was dry and clean. Half of the skin sutures was removed and the same type of bandage with a caudal splint was applied before the donkey was again discharged.

He was represented 6 weeks after the arthrodesis. At that stage he was using the operated limb much more. The bandage was removed as well as the remaining sutures and radiographs were obtained. The implants were still in place and evidence of joint fusion was visible in the carpometacarpal and middle carpal joints. A dorsal new bone proliferation was also observed at the distal aspect of the plates. A new Robert-Jones bandage was applied without the caudal splint.

Fourteen weeks after the surgery, a new assessment was performed. The donkey was nicely using the bandaged limb. The bandage was removed and radiographs were taken. Further evidence of joint fusion was visible. The donkey was walking comfortably with only a mechanical lameness visible ( - Video 1). Recommendations were given to keep him in a small paddock for 3 months.

\section{Video 1}

Donkey walking comfortably with only a mechanical lameness 14 weeks after pancarpal arthrodesis has been performed. Online content including video sequences viewable at: https://www.thieme-connect. com/products/ejournals/html/10.1055/s-00401710503.

The donkey represented 10 months after the surgery for a final evaluation. He had already been out in the field for 2 months. The donkey was walking comfortably. When trotting he had a tendency to drag his toe because of his carpal extension. Radiographs showed the implants to be still in place with complete fusion of the carpal joints (-Fig. 6).

\section{Discussion}

This report presents a case of severe angular limb deformity due to ulnar carpal bone luxation, thought to be of congenital origin, in a young donkey, treated with pancarpal arthrodesis.
Arthrodesis is a radical procedure used for pain relief in case of severe osteoarthritis, to provide stability of a limb after loss of supporting soft tissue structures, or when treating complicated articular fractures. ${ }^{7-9}$ In our case, the ulnar carpal bone appeared caudally luxated, leading to a lateral collapse of the radiocarpal joint and associated severe unstable carpal valgus. Pancarpal arthrodesis was seen as a salvage procedure for this pet donkey to offer him a better quality of life. ${ }^{2}$ Even though a radiocarpal arthrodesis would have been better to preserve some carpal mobility, it is unlikely that it would have been doable and/or have provided enough axial alignment because of both the distal radius deformity and the caudal position of the ulnar carpal bone.

We used LCP plates that are the currently preferred implants for carpal arthrodesis. ${ }^{7}$ Because of the small size of this animal and his bones (width of the proximal metacarpus: $3 \mathrm{~cm}$; width of the distal radius: $4.8 \mathrm{~cm}$ ), we opted for $3.5 \mathrm{~mm}$ LCPs rather than the usual 4.5 or $5.5 \mathrm{~mm}$ LCPs used in horses. ${ }^{6}$ Short plates were used. This approach has recently been developed in horses to avoid placement of implants in the radial and metacarpal diaphyses, limiting the risk of catastrophic fracture. ${ }^{10}$ The longest plate was used on the tension side of this carpus, namely its medial aspect, whereas the lateral plate had more of a buttress function. ${ }^{11,12}$ Locking head screws were used at both plate ends. It could be argued that more LHS, or even a third dorsal plate, could have been added to engage more of the carpal bones and increase the overall stability. However, this was deemed unnecessary because of the low weight of the donkey and the potential interference between implants in such small bones.

The classic approach for carpal arthrodesis typically involves one or two incisions. ${ }^{7,8,12}$ A single dorsolateral incision was performed in our case. It provided us with a comfortable surgical access for placing the dorsolateral and dorsomedial plates owing to judicious tissue retraction, and closure of the skin over the two plates was not an issue, as previously observed. ${ }^{7}$ Minimal invasive insertion of the LCPs, as recently described, ${ }^{10,13}$ was contemplated but an open approach was decided to better assess the frontal and rotational alignment of the limb before implants positioning. An open approach would also have allowed us to perform a wedge resection of the distomedial radius, had it been necessary. ${ }^{5,10}$ As much articular cartilage as possible was removed, but the caudally displaced ulnar carpal bone was difficult to access despite joint flexion. Similarly, because of the small size of the bones, perfect contouring of the LCPs was difficult and a gap of $\sim 6 \mathrm{~mm}$ remained between the dorsomedial plate and the dorsal aspect of the radial carpal bone. These observations might explain the slow radiographic fusion of the joint in this region and could have been overcome using a cancellous bone graft. ${ }^{10,12,13}$ However, bone graft collection from the sternum was judged hazardous because of the small size of the animal and associated risk of penetrating the thoracic cavity. ${ }^{14}$

Limb immobilization was provided using a Robert-Jones bandage with a caudally placed splint without jeopardizing the construct. This approach is similar to cases described by Curtiss and colleagues ${ }^{10}$ and is permitted because of the 


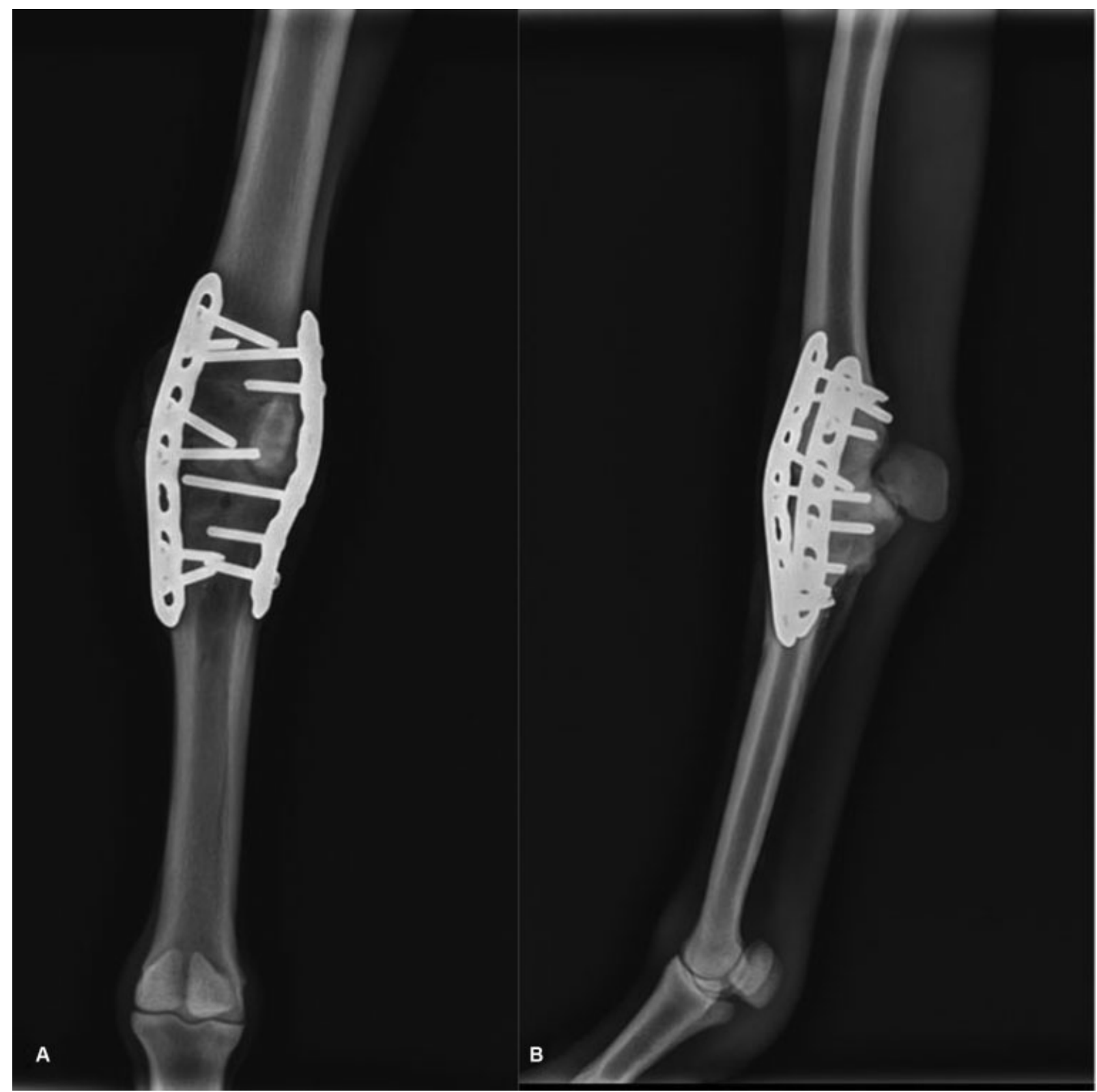

Fig. 6 Radiographs of the left carpus 10 months after arthrodesis has been performed. Note the complete fusion of the carpal joint: (A) dorsopalmar view, (B) lateromedial view.

stability obtained at the joint surface with the fixed-angle construct of the LCP system. ${ }^{6}$

None of the reportedly common complications of carpal arthrodeses (laminitis, infection, implant failure) were observed in our case. ${ }^{7-9,11}$ Once again, this is likely because of the high stability of the construct allowing direct weight bearing on the operated limb and undoubtedly because of the small size of the animal. ${ }^{5,6}$

The dorsal periosteal reaction observed at the distal aspect of the plates might reflect a possible stress concentration at this level where both plate ends were located. Alternatively, it could only be due to the surgical exposure and periosteal trauma. It had no apparent consequence on the outcome.

Our donkey obtained a proper limb alignment, became sound at the walk with only a mechanical lameness and radiographic joint fusion was achieved, which are the desired outcomes of a pancarpal arthrodesis. ${ }^{8,10-12}$

We believe the ulnar carpal bone malposition was congenital in origin because of the well-developed and homogeneous aspect of the bone, the absence of evidence of acute or chronic trauma and because a similar but milder malposition was also present on the contralateral carpus. Additionally, the abnormal shape of the distolateral radial epiphysis is thought to be a consequence of the ulnar carpal bone malposition and absence of opposing articular surface. Not less than six ligaments normally insert on the ulnar carpal bone. ${ }^{15}$ One of them could have been absent or of abnormal length to explain the ulnar carpal bone caudal malposition. Although untreated incomplete ossification of the carpal cuboidal bones when this donkey was born could be an alternative explanation, it is likely that the lateral 
carpal bones would have some degree of deformity, which was not observed. ${ }^{16}$ Similarly, traumatic luxation of the ulnar carpal bone is unlikely in our case because these are typically associated with some degree of soft tissue swelling and joint effusion when they occur in small animals and humans. ${ }^{17-19}$ Finally, no case of individual carpal bone luxation or dislocation could be found in the equine literature without associated complex carpal fracture. ${ }^{20}$

In this unusual case of severe unstable carpal valgus due to luxation of the ulnar carpal bone, pancarpal arthrodesis using two small LCPs proved efficient in fusing the carpal joints and offering a good postoperative comfort.

\section{Ethical Considerations}

The owner of the donkey gave written consent for the surgery to be performed and for inclusion in potential studies. The Research Ethics Committee of the University approved this case report (project REC179-19).

\section{Funding}

None.

\section{Conflict of Interest \\ None declared.}

\section{Acknowledgments}

The authors wish to thank the staff and students of the Onderstepoort Equine Clinic for their help and implication in this case, as well as Dr. Fabrice Rossignol for his surgical advice.

\section{References}

1 Muurlink T. Surgery of miniature horses. Equine Chapter Meeting at the ACVSc Science Week. Gold Coast, Queensland, Australia: John Chopin; 2012

2 Getman LM. Surgical treatment of severe, complex limb deformities in horses. Equine Vet Educ 2011;23(08):386-390

3 Kelmer G, Wilson DA. Bilateral metatarsophalangeal arthrodesis for severe congenital flexor tendon laxity and metatarsophalangeal luxation in a miniature horse. Equine Vet Educ 2007;19(10):547-550

4 Whitehair KJ, Adams SB, Toombs JP, et al. Arthrodesis for congenital flexural deformity of the metacarpophalangeal and metatarsophalangeal joints. Vet Surg 1992;21(03):228-233
5 Whitfield-Cargile C, Watkins JP. Bilateral distal radial epiphysectomy and pancarpal arthrodesis for correction of complex carpal deformities in an American Miniature horse. Equine Vet Educ 2011;23(08):381-385

6 Levine DG, Richardson DW. Clinical use of the locking compression plate (LCP) in horses: a retrospective study of 31 cases (20042006). Equine Vet J 2007;39(05):401-406

7 Lischer CJ, Auer JA. Arthrodesis techniques. In: Auer JA, Stick JA, Kümmerle JM, Prange T, eds. Equine Surgery. 5th edition. Saint Louis: Elsevier; 2019:1374-1398

8 Zubrod CJ, Schneider RK. Arthrodesis techniques in horses. Vet Clin North Am Equine Pract 2005;21(03):691-711, vii

9 Ross MW. The carpus. In: Ross MW, Dyson SJ, eds. Diagnosis and Management of Lameness in the Horse. St. Louis, Missouri: Elsevier; 2011:426-449

10 Curtiss AL, Goodrich LR, Rossignol F, Richardson DW. Pancarpal and partial carpal arthrodesis with 3 locking compression plates in 6 horses. Vet Surg 2018;47(05):692-704

11 Lewis RD. Carpal Arthrodesis-Indications and Techniques. Proc Am Ass Equine Practnrs 2001;47:480-483

12 Bertone AL, Schneiter HL, Turner AS, Shoemaker RS. Pancarpal arthrodesis for treatment of carpal collapse in the adult horse. A report of two cases. Vet Surg 1989;18(05): 353-359

13 Brandenberger O, Rossignol F, Bartke S, Van Bergen T, Vitte A. Carpal arthrodesis using a minimally invasive approach and locking compression plates: three cases. Equine Vet Educ 2018; 30(05):229-236

14 Duan W, Lopez MJ. Bone Grafts and Bone Replacements. In: Auer JA, Stick JA, Kümmerle JM, Prange T, eds. Equine Surgery. 5th edition. Saint Louis: Elsevier; 2019:1314-1326

15 Barone R. Anatomie comparée des mammifères domestiques Tome 2-Arthrologie et myologie. 4th ed. Paris, France: Vigot; 2000:991

16 Levine DG. The normal and abnormal equine neonatal musculoskeletal system. Vet Clin North Am Equine Pract 2015;31(03): 601-613

17 Miller A, Carmichael S, Anderson TJ, Brown I. Luxation of the radial carpal bone in four dogs. J Small Anim Pract 1990;31(03): 148-154

18 Pitcher GDC. Luxation of the radial carpal bone in a cat. J Small Anim Pract 1996;37(06):292-295

19 Lee B-J, Kim S-S, Lee S-R, Jin J-M, Yoon MG, Moon M-S. Palmar scaphoid dislocation associated with dorsal perilunate dislocation: case report. J Hand Surg Am 2010;35(05):726-731

20 Barr ARS, Hillyer MH, Richardson JD. Partial carpal arthrodesis for multiple carpal fractures and subluxation in a pony. Equine Vet Educ 1994;6(05):255-258 